\title{
Sandra Cheilan, Poétique de l'intime. Proust, Woolf et Pessoa
}

\section{Roberta Sapino}

\section{Q OpenEdition}

1 Journals

\section{Edizione digitale}

URL: http://journals.openedition.org/studifrancesi/4521

DOI: 10.4000/studifrancesi.4521

ISSN: 2421-5856

\section{Editore}

Rosenberg \& Sellier

\section{Edizione cartacea}

Data di pubblicazione: 1 settembre 2016

Paginazione: 386-387

ISSN: 0039-2944

\section{Notizia bibliografica digitale}

Roberta Sapino, «Sandra Cheilan, Poétique de l'intime. Proust, Woolf et Pessoa », Studi Francesi [Online] 179 (LX | II) | 2016, online dal 01 septembre 2016, consultato il 18 septembre 2020. URL : http:// journals.openedition.org/studifrancesi/4521 ; DOI : https://doi.org/10.4000/studifrancesi.4521

Questo documento è stato generato automaticamente il 18 settembre 2020.

\section{(c) (i) $\odot$}

Studi Francesi è distribuita con Licenza Creative Commons Attribuzione - Non commerciale - Non opere derivate 4.0 Internazionale. 


\title{
Sandra Cheilan, Poétique de l'intime. Proust, Woolf et Pessoa
}

\author{
Roberta Sapino
}

\section{NOTIZIA}

SANDRA CHEILAN, Poétique de l'intime. Proust, Woolf et Pessoa, Rennes, Presses Universitaires de Rennes, 2015, 428 pp.

1 Di natura spiccatamente comparativa, il volume di Sandra CHEILAN si presenta come un'attenta lettura dell'opera di tre autori rappresentativi della letteratura europea del Novecento (Marcel Proust, Virginia Woolf e Fernando Pessoa), attraverso la lente instabile e rivelatrice del concetto di intime. Concetto che l'autrice ha cura di definire etimologicamente (dall'aggettivo intimus, superlativo di interior) e poi cronologicamente fino al ventesimo secolo, quando la crisi della concezione unitaria del soggetto mette in dubbio la possibilità di trovare nella "vérité de l'intime» un valido fondamento morale, etico ed estetico. Proprio in questo contesto, osserva Cheilan nell'«Introduzione» (pp. 9-27), autori come Proust, Woolf e Pessoa si appropriano della nozione di intime per farne materia di rinnovamento artistico, strumento per esplorare i limiti e le possibilità della rappresentazione romanzesca dell'individuo. Il volume si propone di studiare la loro opera attraverso un quadro teorico composito, che non esita a servirsi degli strumenti della semiotica, della psicanalisi e delle ricerche sull'immaginario, allo scopo di delineare i tratti di una vera e propria "poétique de l'intime» novecentesca. Particolare attenzione è rivolta a quello che Cheilan definisce il «chronotope intimiste», che determina l'intimità psichica, corporea e relazionale, e che è fondato sulle opposizioni interno-esterno, profondità-superficie, individuo appartatogruppo sociale, e su una temporalità essenzialmente retrospettiva.

2 Il discorso si articola su tre sezioni. La prima, intitolata «Le roman intime» (pp. 29-155), situa l'opera dei tre autori da un punto di vista geografico, culturale e letterario, mostrando peculiarità e analogie tra aree complementari. Dall'invenzione del «roman 
intime» operata da Proust ai fenomeni di appropriazione, trasposizione e deviazione del modello proustiano che fecondano l'opera di Woolf, all'esplorazione dell'eredità intimista francese negli scritti di Pessoa, si delinea una cartografia europea articolata, in cui le molteplici zone di influenza emergono come luoghi d'innovazione fecondi («Vers une géopoétique de l'intime», pp. 31-94). Il principio dell'appropriazione dell'altro, dell'inglobamento e della rielaborazione dell'eterogeneo, è poi ricondotto alle dinamiche di posizionamento dell'opera di Proust, Woolf e Pessoa nel campo letterario: il loro rifiuto dei codici autobiografici, la volontà di emancipazione dalle classificazioni tradizionali, e insieme la tendenza all'incorporazione di tematiche e topoi tipici della letteratura personale, permettono a Cheilan di definire il «roman intime» come «roman cannibale» («"Un roman cannibale”: incorporation et détournement des genres intimes», pp. 95-155).

La seconda sezione si concentra sulle «Représentations des intimités» (pp. 157-280). Partendo dalla considerazione che la natura plurale dell'intimità e la sua resistenza alla rappresentazione linguistica necessitano di un approccio di impianto dialogico, Cheilan si sofferma sui momenti in cui la scrittura di Proust, Woolf e Pessoa si sottrae ai discorsi scientifici e letterari dominanti grazie all'elaborazione di una polifonia che si esprime tanto sul piano della rappresentazione dell'universo mentale, quanto su quello dell'espressione linguistica («Des intimités: dialogisme et hétérogénéité de l'intime», pp. 159-215). Il capitolo successivo si addentra «Dans l'intimité du corps» (pp. 217-280): la drammatizzazione del corpo partecipa alla costruzione di una personalità ambivalente e mette in luce questioni complesse quali l'espressione delle emozioni più private, la restituzione di una percezione intima del mondo, l'indagine delle relazioni tra le sfere fisica e psichica.

4 La sezione conclusiva espande il campo di indagine alla «Scénographie intimiste» (pp. 281-395), l'insieme dei dispositivi spazio-temporali nei quali gli autori scelgono di situare le loro avventure introspettive, fantasmatiche, retrospettive. Lo studio dei «Territoires de l'intime» (pp. 285-368), della loro costruzione testuale e della valenza simbolica che assumono nella narrazione, in una costante dialettica tra interno e esterno, domestico ed estraneo, pone una riflessione sullo statuto ambiguo della nozione di intime, definibile tanto sul piano personale di rapporto a sé quanto su quello relazionale di relazione con l'altro. A completamento dell'indagine, Cheilan propone l'analisi di una temporalità mitica e quotidiana, in cui la linearità hegeliana è piegata dai movimenti della memoria e dalle tendenze regressive di un Io che trova nell'infanzia il fondamento della vita soggettiva e nella notte il momento propizio alle divagazioni della - e nella - psiche («Du temps vécu au temps mythique de l'intimité: mouvements de retour et de régression», pp. 369-395). Le conclusioni («Du roman intime au livre-origine», pp. 397-399) propongono infine una riflessione sul ruolo del Libro nella mitologia delle origini tracciata dai tre autori: oggetto capace di operare forme diverse di identificazione e sublimazione, il libro assume un ruolo centrale nell'avventura intima del personaggio e contribuisce a strutturare coerentemente il rapporto dell'Io con se stesso e con il mondo.

In appendice, una piccola galleria di immagini permette di apprezzare i riferimenti iconografici citati; una ricchissima bibliografia conclude il volume e invita a letture ulteriori. 